\title{
Repetitive Mechanical Responses of the Amphibian Skin to Adrenergic Stimulation
}

\author{
I. TASAKI \\ National Institute of Mental Health, NIH, Bethesda, Maryland 20892, USA
}

\begin{abstract}
Summary: Mechanical responses of the amphibian nerve-skin preparation to adrenergic stimulation were investigated by recording pressure changes at the skin surface with a piezoelectric sensor. When a dilute epinephrine (or norepinephrine) solution was applied to the inner skin surface, repetitive mechanical responses, representing quick swelling of the skin repeating at more or less regular intervals of about $1 \mathrm{~min}$,
\end{abstract}

were frequently observed. In about $10 \%$ of the preparations, the skin was found to undergo repetitive quick shrinkage (instead of swelling) under practically indistinguishable experimental conditions. Rapid volume changes occurring in the cytoplasmic gel of the gland cells are considered to be at the base of these repetitive mechanical responses. [Japanese Journal of Physiology, 48, 297-300,1998]

Key words: frog skin glands, epinephrine, repetitive mechanical changes.

The skin glands, mucous and granular, of the frog are known to receive adrenergic innervation [1]. It has been well documented that secretion from the amphibian skin glands can be produced by nerve stimulation $[2,3]$, and by epinephrine (or norepinephrine) application $[4,5]$. In a more recent publication $[6]$, it has been shown that nerve stimulation and epinephrine (or norepinephrine) applied to the inner skin surface both elicit readily detectable mechanical changes considered to underlie the secretory process of the gland cells.

The present study was undertaken to determine the time course of the mechanical changes in the skin gland evoked by adrenergic stimulation. The original aim of the study was to acquire new information about the structural changes in the gland cells involved in the secretion of mucus and granules. In most of the experiments, a piezoceramic bender $[6,7]$ was employed in recording. In response to application of epinephrine (or norepinephrine) to the inner surface, the skin was found to produce distinct mechanical changes repeating at intervals of about $1 \mathrm{~min}$. A striking similarity is noted between the records of these mechanical changes and those published by several of recent investigators [8-10], which show oscillatory changes in the intracellular $\mathrm{Ca}^{2+}$ concentration in a variety of cells.

\section{Materials and Methods}

Nerve-skin preparations of the bullfrog, Rana catesbeiana, were used in most of the experiments. Preparations of the toad, Bufo marinus, were also employed in some experiments. The animals, $12-15 \mathrm{~cm}$ long, were sacrificed by quick decapitation. Fragments of the calf skin, usually the portions innervated by the crural branch of the tibial nerve, were excised with the supplying nerves. Small pieces of the bullfrog dorsal skin were also excised. Isolated nerve-skin preparations were kept in a large volume of aerated and chilled physiological saline solution until they were used for measurements. The composition of the saline solution was as follows: $110 \mathrm{mM} \mathrm{NaCl}, 2.5 \mathrm{mM} \mathrm{KCl}$, $2 \mathrm{mM} \mathrm{CaCl}_{2}, 10 \mathrm{mM}$ glucose, and $5 \mathrm{mM}$ HEPES buffer (pH 7.4).

A nerve-skin preparation was mounted across a shallow plastic chamber with the inner skin surface facing upward. The chamber was provided with a pair of $\mathrm{Ag}-\mathrm{AgCl}$ stimulating electrodes near its edge, and the proximal portion of the nerve was placed on the electrodes. At the bottom surface of the chamber (see the diagrams in Figs. 1 and 2) there was a slightly elevated platform on which the portion of the skin innervated by the nerve branch (recognized by the blood vessels accompanied by the nerve branch) was placed.

Received on April 17, 1998; accepted on June 19, 1998

Correspondence should be addressed to: I. Tasaki, Rm 3E-25, BIdg. 13, NIH, Bethesda, MD 20892, USA. E-mail: itasaki@erols.com 
In the middle of this elevated portion of the skin, a square piece of nylon mesh, approximately $9 \mathrm{~mm}^{2}$ in size, was deposited. Excluding this slightly elevated portion, the entire skin surface was usually covered with a thin layer of normal saline solution (Fig. 2).

The sensor employed for determining pressure changes generated in the skin was substantially the same as those used in several previous studies performed in this laboratory $[6,7]$. A piezoceramic bender (R0505 element purchased from Piezoelectric Products, Inc., New Jersey) is about $1.5 \mathrm{~mm}$ wide, $12 \mathrm{~mm}$ long, and approximately $0.5 \mathrm{~mm}$ thick; it has an electric capacity of roughly $1 \mathrm{nF}$ and a very high resistance. One end of the bender was immobilized and connected to the input of an operational amplifier (OPA 128), which usually had a feedback resistor of $8 \mathrm{G} \Omega$ and a parallel capacitor of about $15 \mathrm{nF}$. The output of the operational amplifier was led to a Data6000 Analyzer (Analogic Corp.) after an additional 10 -fold d.c. amplification. To transmit changes in skin pressure to the bender, a light wooden stylus, $0.5 \mathrm{~mm}$ in diameter and about $12 \mathrm{~mm}$ long, was attached vertically to the other end of the bender. The responsivity of the sensor was calibrated by the procedure described previously $[6,7]$. By aid of a rack-and-pinion device, the bender was lowered from above and the tip of the stylus brought into firm contact with the nylon mesh placed on the skin surface.

Under these experimental conditions, a train of strong electric shocks $(0.5-1 \mathrm{~ms}$ in duration and $10-20 \mathrm{~V}$ in amplitude) applied to the nerve was found to evoke, besides a small variation in the potential difference across the skin [6], a distinct rise in the pressure in most of the preparations. With a train of shocks repeating at $10 \mathrm{~Hz}$, the pressure rise started $0.4-0.5 \mathrm{~s}$ after the onset of stimulation and then rose within $0.6-1.5 \mathrm{~s}$ to its maximum level of usually 1.6-3.0 dyn (measured by way of the $9 \mathrm{~mm}^{2}$ nylon mesh placed on the skin). To facilitate comparison between these responses to nerve stimulation and those elicited by adrenergic stimulation described later, an example of the records of responses to nerve stimulation is presented in Fig. 1. By use of a modified optical method [7], these stimulating electric shocks were shown to produce, in most preparations, a transient increase in the skin thickness of $0.7-5 \mu \mathrm{m}$ in amplitude. The mechanical responses of the skin to adrenergic stimulation were examined by using these preparations, which were found capable of responding to nerve stimulation.

The drugs, epinephrine and norepinephrine, were purchased from Sigma Chemical Co. By using a small pipette, a known volume (usually $20 \mu \mathrm{l}$ ) of saline solu-
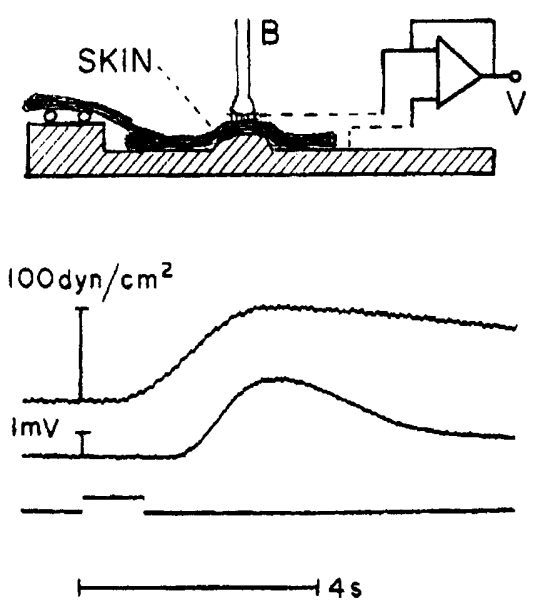

Fig. 1. Simultaneous recording of mechanical (top) and electric (bottom) responses of a bullfrog nerve-skin preparation to repetitive nerve stimulation. The experimental setup employed is illustrated schematically at the top. B represents the stylus attached to the tip of the piezoelectric bender. $V$ represents the output of the operation amplifier employed to record electric responses by using fine silver wires connected to the upper and lower surfaces of the skin. The lowermost oscillograph trace indicates the duration of the train of stimuli $(10 \mathrm{~Hz})$ employed.

tion containing the drug $(0.2-60 \mu \mathrm{M})$ was quickly delivered to the portion of the skin covered by the nylon mesh. Mechanical artifacts evoked by delivering about the same quantity of normal drugfree solution could be readily distinguished from physiological responses of the skin, which invariably had a regenerative rising phase. It is to be noted in this connection that electric responses to adrenergic stimulation are too small to be recorded by the method illustrated in Fig. 1.

All the experiments were performed at room temperature $\left(20-22^{\circ} \mathrm{C}\right)$.

\section{Results}

An example of the records of mechanical responses of the bullfrog skin to norepinephrine stimulation is shown in Fig. 2, left. The arrows marked " $R$ " in the figure indicate the time at which a small quantity of normal saline solution was delivered to the inner surface of the skin. It is seen that an abrupt pressure rise was evoked in association with every delivery. When the same quantity of the saline solution containing $60 \mu \mathrm{M}$ norepinephrine was delivered (at the moment marked "NA"), the small mechanical artifact associated with the solution delivery was followed by a smooth, regenerative rise in the pressure, indicating the beginning of a physiological response. As compared with the mechanical responses to nerve stimulation (Methods), these responses had a slightly slower rise and were smaller in amplitude. The falling phase 


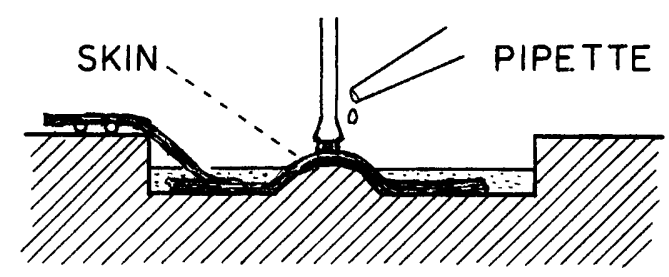

Fig. 2. Demonstration of mechanical responses of the bullfrog skin to adrenergic stimulation. The schematic diagram at the top illustrates the experimental setup employed (Methods). The left bottom record was obtained by applying $20 \mu \mathrm{l}$ of normal saline solution (R) and $60 \mu \mathrm{M}$ norepinephrine solution (NA) at the moments marked by the arrows; the response evoked was roughly $20 \mathrm{dyn} / \mathrm{cm}^{2}$ in amplitude.
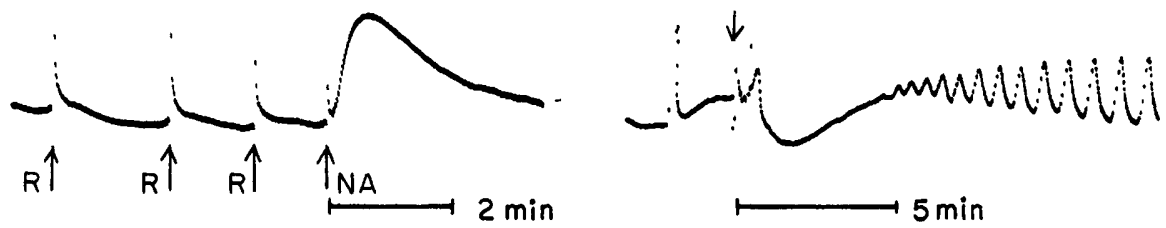

The right bottom record shows a mechanical response to nerve stimulation (roughly $20 \mathrm{dyn} / \mathrm{cm}^{2}$ ), followed by responses evoked by appli cation of $20 \mu \mathrm{l}$ of $20 \mu \mathrm{M}$ epinephrine.

was always much longer than the rising phase. The effect of epinephrine was similar to that of norepinephrine.

Figure 2, right, shows an example of the records taken on a slow time base under similar experimental conditions. It is seen that after a latent period of about $4 \mathrm{~min}$, small responses repeating at more or less regular intervals began to appear, and the response amplitude gradually increased. In most of the preparations examined, the response amplitude remained nearly constant during 20 and $40 \mathrm{~min}$ after the onset. The response amplitude during this roughly steady stage was comparable to or slightly larger than the one evoked by nerve stimulation. The response intervals were generally $0.8-1.5 \mathrm{~min}$. Usually, the repetitive firing of responses subsided rapidly after this period.

Repetitive mechanical responses to adrenergic stimulation were recorded from nearly 50 nerve-skin preparations. The pattern of the observed pressure changes were found to vary greatly among these preparations. Record A in Fig. 3 shows the pattern observed in about $65 \%$ of the preparations. It is seen in this record that the duration of the rising phase of the pressure change was far shorter than that of the falling phase; the responses (taken on a slow time base) had an appearance of repetitively fired spikes that were pointing upward. In these preparations, the gland cells contributing to the generation of these responses are considered to be in a shrunken state at rest, and they repetitively experience regenerative swelling.

Record B in the figure is an example of the pattern encountered in about $10 \%$ of the preparations. In this record, the duration of the falling phase of the pressure changes was very short; consequently, repetitively fired spikes were pointing downward. In these preparations, the gland cells are considered to be in their swollen state initially, and they experience brief shrinkage repetitively. In the records taken from the remaining $25 \%$ of the preparations from which repeti-

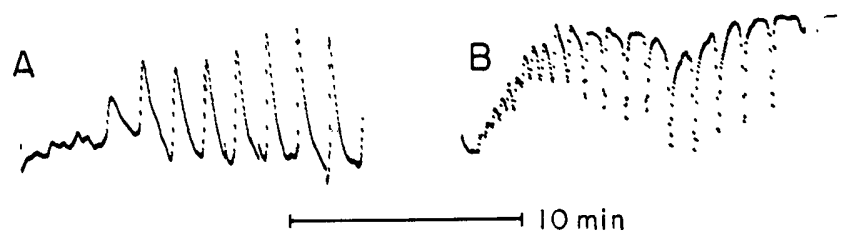

Fig. 3. Two examples of records showing repetitive firing of mechanical responses evoked by application of $20 \mu \mathrm{l}$ of about $15 \mu \mathrm{M}$ epinephrine to the bullfrog skin. In Record $\mathbf{A}$, the largest responses were roughly $90 \mathrm{dyn} / \mathrm{cm}^{2}$ in amplitude, and their intervals were about $1.5 \mathrm{~min}$. The corresponding values in Record $\mathbf{B}$ were $72 \mathrm{dyn} / \mathrm{cm}^{2}$ and $1.2 \mathrm{~min}$.

tive mechanical responses were recorded, the duration of the rising phase of the pressure change was comparable to that of the falling phase; the gland cells in these preparations were, apparently, oscillating between their shrunken and swollen states.

The finding that the gland cells of some preparations exist in their swollen state at rest (Record B in Fig. 3) is not surprising. Although most nerve-skin preparations examined were found to respond to nerve stimulation with a transient swelling (Methods), several cases were encountered in which the sign of the evoked responses was definitely opposite to that seen in most of the preparations. Nerve stimulation was found, in some preparations, to generate a transient decrease of the pressure at the skin surface. On a few occasions, the sign of the response was found to reverse during the observation. (Note also the production of negative thermal responses to nerve stimulation in some preparations [6].)

\section{Discussion}

It is interesting to note that a striking resemblance exists between the records of mechanical responses presented in this communication and those showing the so-called $\mathrm{Ca}^{2+}$ waves in a variety of cells [8-10]. For example, the latent period, the frequency, and the 
pattern of spike generation representing $\left[\mathrm{Ca}^{2+}\right]_{\mathrm{c}}$ variation in the pancreatic acinar cells stimulated with CCK-8 [9] are very similar to those of the records taken from the frog skin. In the parotid glands, Foskett et al. [10] have shown that the observed variation in the intracellular $\mathrm{Ca}^{2+}$ concentration is accompanied by an increase in the volume of the cell. It is reasonable, therefore, to assume that a rhythmical variation in the intracellular concentration of unbound (i.e., osmotically active) $\mathrm{Ca}^{2+}$ is at the base of the repetitive mechanical responses. It should be remembered in this connection that the excitation process in the nerve fiber is associated with a regenerative swelling that can be suppressed by substituting $\mathrm{Ca}^{2+}$ in the medium with monovalent cations [7].

The gland cells are expected to have negatively charged macromolecules in their cytoplasm (e.g., Foskett et al. [10]). The experimental findings described in this communication may be explained on the assumption that the gel formed by these macromolecules is maintained, by virtue of the cellular metabolism, in a state close to the threshold for transition between its shrunken and swollen states. Note that the volume of a negatively charged macromolecular gel can be altered drastically by changing the fraction of the free divalent cations in the medium containing both monovalent and divalent cations [11]. When this gel is kept close to its transition threshold, a large volume change can be induced in it by a minute perturbation of its environment, and the change induced can be either swelling or shrinkage.

In conclusion, the importance of measurements of mechanical changes in the gland cells in the elucida- tion of the secretory processes is emphasized.

\section{REFERENCES}

1. Sjöberg $E$ and Flock $\AA$ : Innervation of skin glands in the frog. Cell Tissue Res 172: 81-91, 1976

2. Brucke ETh: Über die sympatische Innervation der Krötenhaut. Z Biol 74: 99-112, 1921

3. Uyeno K: The sympathetic innervation of the skin of the toad. J Physiol (Lond) 56: 359-366, 1922

4. Seldin JP and Hoshiko T: Ionic requirement for epinephrine stimulation of frog skin gland secretion. J Exp Zool 163: 111-114, 1966

5. Benson BJ and Hadley ME: In vitro characterization of adrenergic receptors controlling skin gland secretion in two anurans Rana pipiens and Xenopus laevis. Comp Biochem Physiol 30: 857-864, 1969

6. Tasaki I and Byrne PM: Thermal and mechanical responses of the amphibian skin to nerve stimulation. Jpn J Physiol 41: 567-576, 1991

7. Tasaki I and Iwasa K: Rapid pressure changes and surface displacements in the squid giant axon associated with production of action potentials. Jpn J Phyiol 32: 69-81, 1982

8. Cuthbertson KSR and Cobbold PH: Phorbol ester and sperm activate mouse oocytes by inducing sustained oscillations in cell $\mathrm{Ca}^{2+}$. Nature 316: 541-542, 1985

9. Habara $Y$ and Kanno T: Dose-dependency in spatial dynamics of $\left[\mathrm{Ca}^{2+}\right]_{c}$ in pancreatic acinar cells. Cell Calcium 12: 533-542, 1991

10. Foskett JK, Wong MMM, Sue-A-Quan G, and Robertson MA: Isosmotic modulation of cell volume and intracellular ion activities during stimulation of single exocrine cells. J Exp Zool 268: 104-110, 1994

11. Tasaki I and Byrne PM: Discontinuous volume transitions induced by calcium-sodiumion exchange in anionic gels and their neurobiological implications. Biopolymers 34:209-215, 1994 